\title{
Cartografias da Resistência: as vozes das manifestações de
}

rua

\author{
Cartographies of the Resistance: the voices from street protests \\ Regina BARACUHY \\ Universidade Federal da Paraíba (UFPB) \\ http://orcid.org/0000-0003-2867-6806
}

RESUMO: Este artigo objetiva cartografar práticas discursivas, materializadas nos cartazes e faixas das manifestações de rua ocorridas no Brasil (2019-2020). A rua é o palco de produção de subjetividades. Nossa análise, baseada no referencial teórico dos Estudos Discursivos Foucaultianos, utiliza as noções de enunciado, sujeito, dispositivo, corpo, poder, biopolítica, governamentalidade, dentre outras. Esta cartografia espacial, feita à luz de uma arqueogenealogia, tem como fim, não apenas discutir as relações de poder por meio do inventário de técnicas e táticas discursivas, nem somente mapear produções de subjetividade para descrever/analisar como somos e por que somos assim, mas sobretudo diagnosticar o tempo presente com a problematização do funcionamento do território urbano para recusarmos o que nos é imposto e apontarmos possibilidades de sermos diferentes.

PALAVRAS-CHAVE: Discurso. Foucault . Movimentos de Rua. Resistencia.

\begin{abstract}
This paper focuses on discursive practices materialized through posters and written flags during street protests, which took place in Brazil 2019-2020. Streets one of the stages for the production of subjectivities. This analysis is based on the Foucaultian theoretical framework of Discursive Studies. Using this framework, the concepts of enunciation, subject, dispositive, body, power, biopolitic, and governmentality, among others are applied to the analysis This archaeological and genealogical spatial cartography discusses power relations through an inventory of discursive techniques and tactics seeking understanding the production of subjectivities. The goal is to analyze how are we the way we are, and why we are the way we are. Beyond that, this paper offers a diagnosis of the present time problematizing how the urban territory works to refuse what is imposed to us, and therefore the possibility to be different.
\end{abstract}

KEYWORDS: Discourse. Foucault. Street Protests. Resistance

\section{Arqueologia de uma paixão}

Escavar é preciso, nos diria Michel Foucault. Ele nos mostra, com a sua reflexão crítica sobre o sujeito, a importância do discurso e da história. Interessa-lhe, como 
sabemos, a história serial, não-linear, descontínua, com suas rupturas, suas brechas, por onde saberes e poderes se entrelaçam na constituição das práticas discursivas que movem a roda da História ${ }^{1}$. O olhar foucaultiano se volta para a história das vozes infames, com o foco voltado para aquilo considerado periférico, menor, marginal, fronteiriço. Sua obra, como diz o paraibano Durval Muniz Albuquerque Júnior (2008: p.9):

fez aparecer uma nova geografia de nosso pensamento e de nossas práticas ao ir buscar naquilo que é desviante, criminoso, invisível, ameaçador, as próprias operações fundamentais de constituição do que somos e daquilo que fizemos e fazemos de nós mesmos.

Neste dossiê, comemorativo dos 50 anos de "A Arqueologia do Saber", peço licença a você, caro leitor, para falar um pouco da história de como o estudo dessa obra inaugurou para mim um modo de existência, um olhar para mim mesma e para outrem, com o intuito de problematizar práticas discursivas e não-discursivas, de avaliar constantemente meu papel de professora e de pesquisadora da área da Linguística no campo das Ciências Humanas. Foucault foi um divisor de águas em minha vida e não falo somente na esfera profissional, porque estudar o pensamento foucaultiano não é uma tarefa acadêmica, mas um projeto de vida.

Tudo começou em Araraquara, no ano de 2000, na rua Quinze de Novembro, em um apartamento do Edifício Solimões, décimo terceiro andar, onde um grupo de professores-pesquisadores de diversas universidades brasileiras, de norte a sul do país, grande parte orientandos da professora doutora Rosário Gregolin (UNESP), se reuniam para ler "A Arqueologia do Saber" quinzenalmente às quintas-feiras. Eis a nossa meta! A própria Rosário já nos dizia à época que havia lido várias vezes a referida obra, mas que a cada leitura era uma nova descoberta. Imagine para nós que estávamos começando a nossa empreitada de compreender um dos teóricos mais complexos do nosso tempo e por isso mesmo, fascinante.

Foram anos de grande e coletivo aprendizado que me movimentaram intelectual e existencialmente e me levaram a mudanças na minha forma de ver, de pensar e de agir na sociedade em que vivo. Pensar com Foucault para vislumbrar as chaves da caixa de

\footnotetext{
${ }^{1}$ Este trabalho é fruto da apresentação oral feita na mesa-redonda "Discurso, Poder e Governo dos Vivos", ocorrida na Universidade Estadual de Maringá em outubro de 2019, por ocasião do evento comemorativo dos 50 Anos de A Arqueologia do Saber, intitulado “ (Re)Ler a Arqueologia do Saber Hoje nos Estudos Discursivos da Linguagem: 50 anos”, organizado pelo GT Estudos Discursivos Foucaultianos da ANPOLL, sob a coordenação do Prof. Dr. Pedro Navarro.
} 
ferramentas em um labirinto de palavras. Palavras-lâmina que me punham a refletir, demolindo minhas certezas, cortando-as afiadamente para descortinar outros horizontes com um turbilhão de inquietantes novidades teóricas que discutíamos muitas vezes com a ajuda dos comentadores daquela obra específica para compreendermos as ideias do arquivista dos saberes. Ele nos desafiava a pensar sobre "quem somos nós hoje" para refletirmos sobre e recusarmos as identidades que nos são socialmente impostas. Estávamos na virada do século, do XX para o XXI, período em que fiz meu Doutorado na UNESP.

Claro que não lemos somente esta obra, mas ela foi sem dúvida, basilar para aquele grupo de linguistas que se impuseram como tarefa estudar o pensamento foucaultiano no campo da Análise do Discurso, a fim de problematizar o sujeito e suas práticas, discursivizadas em materialidades diversas. A leitura de "A Arqueologia do Saber" nos trouxe as chaves para abrir a caixa de ferramentas conceituais de Foucault.

Trata-se de um livro fundamental, porque lá estão os conceitos-chave de enunciado, formação discursiva, arquivo, discurso, campo associado, dentre outros, indispensáveis para se empreender uma análise discursiva de diferentes objetos, textuais, imagéticos, semiológicos. Não se trata de aplicar tais conceitos a um corpus, como muitas vezes é feito no campo da Linguística, mas de utilizar as ideias foucaultianas para analisar a história do presente.

Compreender a articulação dos três grandes eixos da sua obra: poder, saber e sujeito, privilegiando a esfera do discurso e a produção histórica da verdade, foi uma das principais lições intelectuais que aprendemos com Foucault. Além disso, trabalhar com este autor nos ensina a sermos, à sua semelhança, arquivistas e cartógrafos do nosso tempo, a fim de interrogarmos o solo epistemológico e político do presente, não apenas para descrever suas redes discursivas de saber e poder, mas sobretudo como forma de intervir nelas.

Dessa historieta da nossa paixão por Foucault, nasceu meu grupo de pesquisa, o CIDADI - Círculo de Discussões em Análise do Discurso -, cujas pesquisas apontam para duas direções:

- a investigação das práticas discursivas do sujeito contemporâneo, para analisar seus modos de objetivação/subjetivação no espaço heterotópico da web;

- a análise cartográfica, na dimensão espacial da cidade, das práticas de governamentalidade (governo de si e do outro) e dos lugares possíveis da resistência, para verificar os saberes e poderes que se materializam nas vozes das minorias, dos que 
vivem à margem, dos que são invisíveis na multidão dos anônimos, mas que sempre procuram brechas para fazer-se ouvir.

Todas as nossas pesquisas se norteiam pelo método arqueogenealógico.

Foucault, ao longo da sua trajetória acadêmica, em seus livros e entrevistas, não pretendeu produzir uma teoria discursiva ou criar um campo do saber cujo objeto seria o discurso, no entanto, em uma de suas entrevistas, intitulada "Diálogo sobre o Poder" e publicada nos Ditos e Escritos IV, ele ressalta que uma certa "análise do discurso" estava no cerne das suas preocupações:

Eu me dei como objeto uma análise do discurso, fora de qualquer formulação de ponto de vista. Meu programa não se fundamenta tampouco nos métodos da linguística. A noção de estrutura não tem nenhum sentido para mim. O que me interessa, no problema do discurso, é o fato de que alguém disse alguma coisa em um dado momento. Não é o sentido que eu busco evidenciar, mas a função que se pode atribuir uma vez que essa coisa foi dita naquele momento. Isto é o que eu chamo de acontecimento. (...) (FOUCAULT, 2003, p.249)

Ao considerar o discurso como acontecimento, ele salienta que a sua preocupação não era com a descrição gramatical da língua - aspecto que se opõe ao pensamento saussureano -, mas considerar o discurso em uma dimensão histórica, com valor de acontecimento.O filósofo em pauta tampouco elaborou um método para fazer suas análises, no entanto, os críticos e estudiosos da sua obra, a posteriori, a partir da investigação da sua obra, designaram o que se convencionou chamar de "método arqueogenealógico", constituído pelos estudos desenvolvidos pelo filósofo em suas fases arqueológica e genealógica. Um método de análise que "escava" da história as condições de emergência dos discursos, a sua capacidade de circulação e a sua possibilidade de transformação.

O objetivo do arqueólogo é investigar as práticas discursivas que formam o saber de uma época, os arquivos, isto é, os enunciados efetivamente ditos e o funcionamento dos discursos. Já o genealogista, ele estuda as (micro)relações de poder e seus efeitos, em diferentes dispositivos para diagnosticar e compreender o modo como o poder se exerce nos processos de subjetivação. As direções de análise apontadas pela arqueologia e pela genealogia (do poder e da ética) se estabelecem como dois conjuntos que se complementam, sendo sua diferença, não tanto de objeto ou de domínio, mas de ponto de ataque, de perspectiva e de abrangência. Em suma, o método ou perspectiva arqueogenealógica nos permite problematizar os efeitos de poder vinculados a uma rede 
de saberes que produzem sujeitos constituídos por práticas discursivas e por elas subjetivados permanentemente.

Entendemos que múltiplas relações de poder, constituídas por táticas e estratégias específicas, configuram uma geopolítica urbana. Propomos pensar a população na materialidade discursiva da cidade e a cidade como realidade biopolítica na sociedade de controle. A fim de analisarmos as discursividades urbanas, interessanos como os espaços afetam e são afetados pelas práticas cotidianas do sujeito urbano; quais os saberes que legitimam tais práticas e objetivam tais sujeitos, modelando seus corpos, seus comportamentos, disciplinando-os, normalizando-os, limitando seus espaços de liberdade. Além disso, importa-nos, sobremaneira, verificar como os sujeitos se subjetivam no espaço urbano, mesmo tendo seus dizeres organizados, normalizados pelas táticas e estratégias sutis dos dispositivos de saber-poder.

Foucault (1987) pensa o discurso como uma prática social que obedece a regras históricas, atreladas ao tempo e ao espaço e que definem as condições de exercício da função enunciativa. Interrogamos por que um dado enunciado emergiu e não outro em seu lugar. Estudamos, a partir de uma dada formação social, um conjunto de enunciados, efetivamente produzidos por sujeitos sociais para compreendermos as relações que eles mantêm entre si e com o domínio associado que os margeia.

A partir dos anos 70, seu interesse deslocou-se do eixo do saber para o eixo do poder e da ética. As noções de governo e de governamentalidade nos permitem entender por que é o sujeito e não o saber ou o poder o tema geral das investigações de Foucault (CASTRO, 2009, p.190-191). Por deslocamentos, não entendemos abandonos, mas sim extensões, ampliações do campo de análise. O estudo da governamentalidade está ligado às artes de governar e inclui, por um lado, o governo de si (pautado pela Ética), o governo dos outros (as formas políticas de governamentalidade) e as relações entre o governo de si e dos outros, que implicam estratégias de poder e resistência.

\section{Cartografias da Resistência: as vozes das ruas}

O título que atribuímos a esse texto decorre do nosso objetivo: cartografar, no espaço urbano, os dispositivos de saber-poder que normalizam as práticas discursivas do sujeito. Para tanto, abordaremos as práticas de governamentalidade e movimentos de resistência em manifestações de rua ocorridas no Brasil durante os anos de 2019 e 2020, a partir da análise discursiva de alguns cartazes, faixas e banners, a fim de 
evidenciarmos as fraturas, as brechas e os rearranjos, por meio dos quais o sujeito se subjetiva no espaço urbano.

Deleuze (2005) refere-se a Michel Foucault como "um novo cartógrafo" e Durval Albuquerque Júnior (2008) nomeia o filósofo como "cartógrafo do nosso tempo do nosso mundo", definindo-o como "o cartógrafo das margens", ou seja, aquele que mapeia, perscruta, olha as camadas do terreno, as dobras, as falhas, desloca o olhar do que sempre foi colocado como central, visível, essencial, para tornar visível o que sempre foi colocado às margens, às bordas, como criminoso, ameaçador.

Quando pensamos em fazer uma análise cartográfica da cidade, temos em mente uma cartografia social que, diferentemente da tradicional, cujo objetivo é traçar mapas de territórios, relevo e distribuição populacional, vai se ocupar dos mapas de relações de força, que envolvem agenciamentos de saberes e poderes com suas táticas e estratégias, materializadas em enunciados, em jogos de objetivação e subjetivação, em práticas de resistência e liberdade, estabelecendo múltiplas e diferenciadas relações, onde o poder opera um esquadrinhamento de todo o campo social.

Esta cartografia espacial, feita à luz de uma arqueogenealogia, tem como fim, não apenas discutir as relações de poder por meio do inventário de técnicas e táticas discursivas, nem somente mapear produções de subjetividade para descrever/analisar como somos e por que somos assim, mas, sobretudo diagnosticar o tempo presente com a problematização do funcionamento do território urbano para recusarmos o que nos é imposto e apontarmos possibilidades de sermos diferentes.

É sobre cartografar essas práticas discursivas urbanas, materializadas em enunciados, que irrompem no espaço urbano, que pretendemos nos deter neste trabalho, especificamente, nas manifestações de rua ocorridas nos anos de 2019 e 2020 no Brasil. A rua é o palco de produção de subjetividades. Os cartazes, faixas, banners materializam os anseios da população. Espaços que nos rodeiam, que nos cercam, que nos definem, espaços de visibilidade para vozes anônimas, ou no dizer foucaultiano, de vozes infames. 


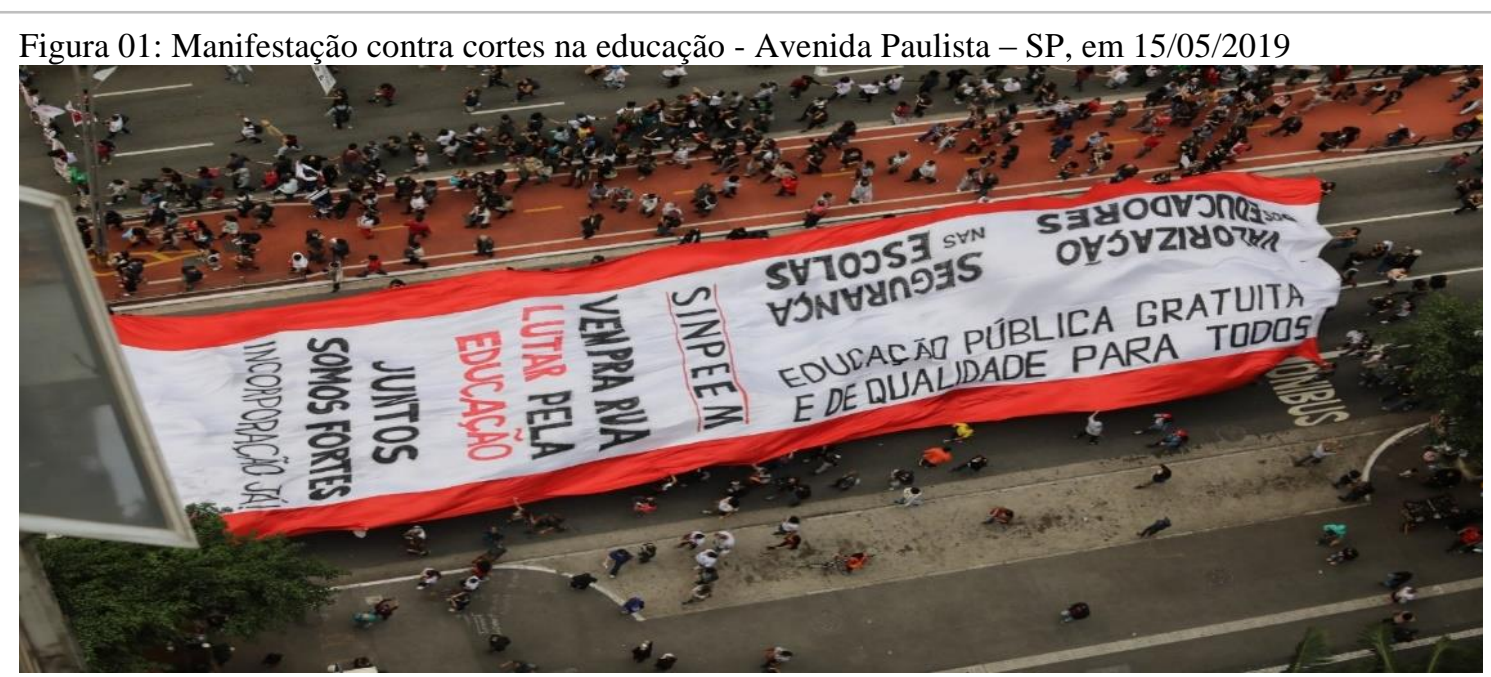

Disponível em: https://www.correiodopovo.com.br/not\%C3\%ADcias/geral/manifesta\%C3\%A7\%C3\%B5es-em-v\%C3\%A1 riascidades-pedem-manuten\%C3\%A7\%C3\%A3o-de-verbas-para-universidades-1.339213

As manifestações de rua são acontecimentos da história de presente. Cartografar o grito das ruas expresso nos cartazes dos manifestantes é um ato político para fazer emergir os jogos de poder que constituem o espaço urbano, é ressaltar os momentos nos quais as resistências ganham espaço e se chocam contra o poder governamental. Se o poder existe numa rede vasta e multiforme de relações, os pontos de resistência também se apresentam como multiplicidade e como focos. Como afirma Foucault (2006, p.81): “É preciso ao mesmo tempo, espreitar, por baixo da história, o que a rompe e a agita".

Em 2019, vimos manifestações de rua pró e contra o governo do presidente Jair Bolsonaro. Temas como a Reforma da Previdência e Cortes na Educação dividiram a opinião popular. Também em 2020, a pandemia do coronavírus no Brasil ganha contornos singulares, pois além da crise sanitária, temos também uma crise política. Apesar de todos os apelos da Organização Mundial de Saúde (OMS) para se evitarem aglomerações, a fim de não haver um contágio em massa da COVID-19, as pessoas saíram às ruas para manifestar seu apoio ou repúdio às condutas do presidente. 
Figura 02 - Cartazes de manifestações de rua - João Pessoa em 15/05/2019

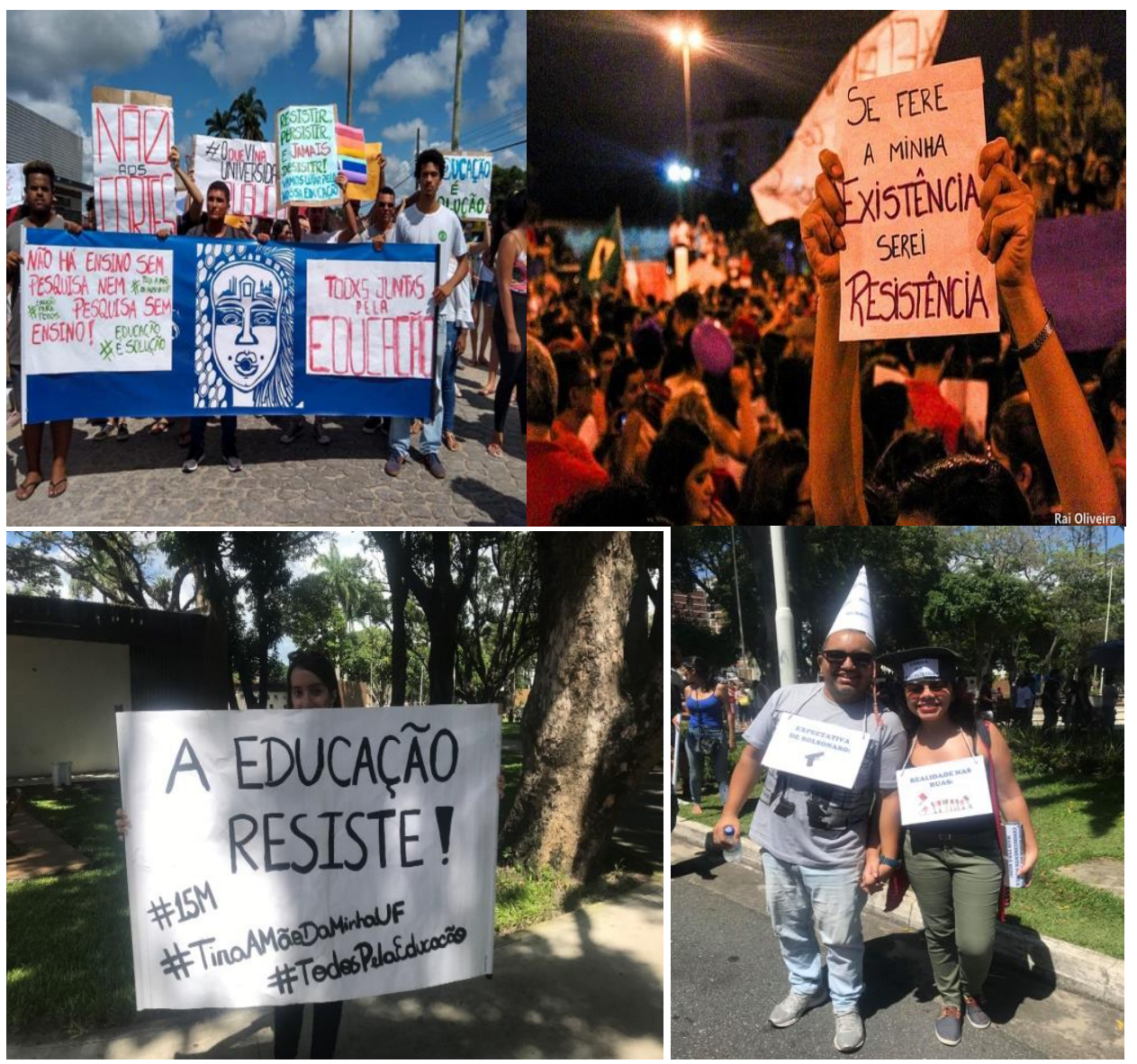

Fotografias: Arquivo pessoal de Regina Baracuhy

Em “A Arqueologia do Saber", Foucault afirma que o enunciado é um átomo do discurso, ou seja, é a unidade básica de análise. Trata-se na verdade, de uma função - a função enunciativa - que não pode ser exercida "sem a existência de um domínio associado, um espaço colateral, uma vez que o enunciado tem sempre margens povoadas por outros enunciados" (FOUCAULT, 1987, p.109/112). E conclui: "Todo enunciado compreende um campo de elementos antecedentes em relação aos quais se situa, mas que tem o poder de organizar e de redistribuir segundo relações novas" (FOUCAULT, 1987, p.143).

A série enunciativa, que se dá a ler nos cartazes fotografados, é composta por vários enunciados precedidos por hashtags como \#EducaçãoÉSolução, \#TiraAMãoDaMinhaUF e \#TodosPelaEducação. O gênero hashtag invade também as ruas, trazendo para elas, a conexão dialógica com as redes digitais, onde ele inicialmente apareceu. Tanto nas ruas como nas redes, o grito dos insurgentes produziu uma memória coletiva e transgressora. 
A utilização de hashtags, que compõem um dado enunciado, o reenvia para um domínio de memória no espaço digital, onde ele se "acumula", ou seja, ele é armazenado conjuntamente, de modo que a "memória do acontecimento" se deposite em um mesmo espaço digital para quem quiser acessá-lo. Pode ser a mesma materialidade (por exemplo, \#TodosPelaEducação), mas a singularidade decorre de os sujeitos serem diferentes e os sentidos também. A circulação incessante de séries parafrásticas de enunciados produz verdades para o sujeito.

Verificamos, nos muitos enunciados utilizados pelos manifestantes das ruas, um "efeito-hashtag" ou efeito-acúmulo, pois as hashtags são conservadas, transmitidas e incessantemente repetidas, a partir de um regime de materialidade (são recorrentes em materialidades diversas, cartazes, faixas, banners), formando uma rede enunciativa, cuja memória se cristaliza por meio de hashtags, que "entram na ordem das contestações e das lutas e tornam-se tema de apropriação ou de rivalidade" (FOUCAULT, 1987, p. 121). Entre o enunciado e o que ele enuncia, há necessariamente uma relação que envolve os sujeitos, a história e a memória.

Ainda sobre os registros fotográficos anteriormente exibidos, vemos vários cartazes que expõem as vozes insurgentes das ruas, palco de reverberações sociais. Pensando os enunciados com valor de acontecimento, uma vez que são singulares e efetivamente produzidos por sujeitos sociais em condições sócio-históricas específicas, vemos que eles funcionam como "um nó em uma rede", provocando fissuras nas relações de saber-poder e criando novos modos de subjetivação.

Para Foucault, o controle da sociedade sobre os indivíduos começou no corpo, com o corpo, pois foi no biológico, no somático, no corporal que investiu a sociedade capitalista. O poder incide sobre o corpo, nele encontra a materialidade através da qual consegue se exercer. Diz ele: "O corpo é uma realidade biopolítica" e a Medicina, uma estratégia biopolítica. (1979, p.80). Essa medicalização social funciona como uma estratégia de conduta dos corpos da população.

Em 2020, no Brasil, podemos observar como as estratégias biopolíticas envolvem a polêmica em torno do uso da hidroxicloroquina no tratamento da Covid 19. Por um lado, há um consenso médico sobre seu uso e eficácia em relação ao tratamento do vírus, por outro, o presidente, respaldado em um discurso anticientífico, faz apologia do medicamento, é garoto-propaganda da hidroxicloroquina, apesar de ser amplamente divulgado seus efeitos colaterais nocivos à saúde. Embora aceita por parte da população como uma verdade, esta forma de governo do corpo, baseada no racismo, no sexismo e 
no negacionismo do discurso científico encontra diferentes formas de resistência e está presente nas manifestações de rua.

Os enunciados nos cartazes acima discursivizam estratégias de confronto contra os desmandos do atual (des)governo. Corpos-panfletos, corpos-objeto, marcados, tatuados com palavras de ordem como "vidas negras importam", em confronto com a ordem estabelecida, reivindicando seus direitos em um grito coletivo de insatisfação. Corpos em movimento, que se subjetivam com a experiência de si para si e de si para os outros. Sujeitos engajados na luta coletiva, que ao afirmarem seus posicionamentos políticos, se subjetivam e recusam as identidades que lhe são impostas, produzindo uma ontologia do presente.

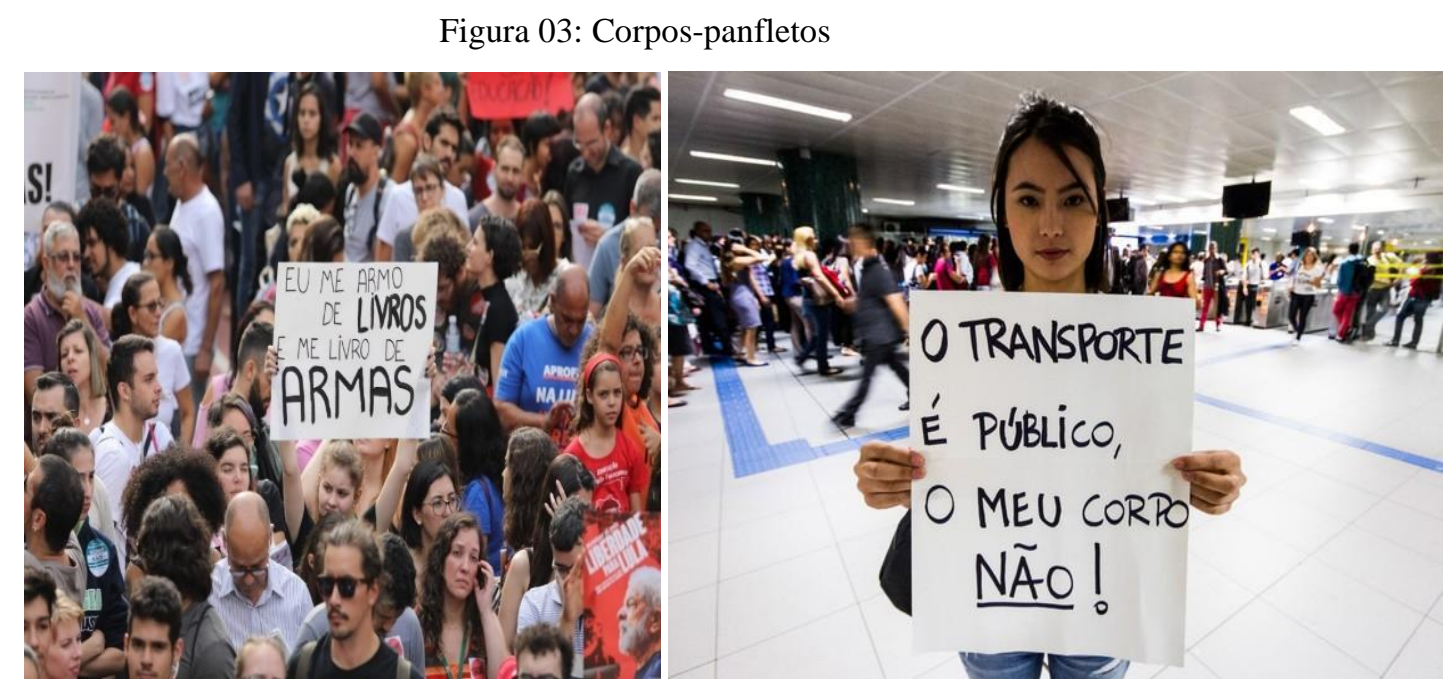

Disponível em: http://g1.globo.com/sao-paulo/noticia/2015/08/coletivos-feministas-fazemprotesto-contra-abuso-sexual-no-metro-de-sp.html Acesso em: 15 de maio 2019

Foucault (1979, p. 65) descreve o corpo como "superfície de inscrição dos acontecimentos". Os cartazes das manifestações de rua expõem a prática discursiva da resistência popular, materializada em inúmeros enunciados, tais como: "Eu me armo de livros e me livro das armas" (crítica à política de incentivo ao armamento da população feita pelo presidente Bolsonaro) e "O transporte é público, o meu corpo não" (denúncia feita a respeito dos inúmeros casos de violência sexual sofrido por mulheres nos transportes públicos do Brasil). Tais enunciados, associados a muitos outros nas/das ruas, compõem uma "linha de fuga" (Deleuze, 1990) do dispositivo de saber-poder que rege o comportamento populacional. Esgarçam o tecido social da história e através de redes discursivas de indignação e esperança, constroem a narratividade das ruas, dão 
visibilidade, jogam luzes para as vozes infames e delineiam uma topografia urbana da (in)visibilidade.

Parafraseando Foucault (1979), diríamos que os cartazes exibem corpos inteiramente marcados de história e a história arruinando os corpos. Conforme Deleuze (2005, p.35), “o poder não tem homogeneidade; define-se por singularidade, pelos pontos singulares por onde passa" e o corpo, acrescentaria Foucault, sempre pode ser um suporte para a emergência de discursos. Consideramos que o corpo está “diretamente mergulhado num campo político (...) investido de relações de poder e de dominação". (FOUCAULT, 2014, p.29). É através dos corpos que se agregam/separam, se incluem/excluem os sujeitos no território urbano.

Figura 04: Mulheres em manifestação na Avenida Paulista

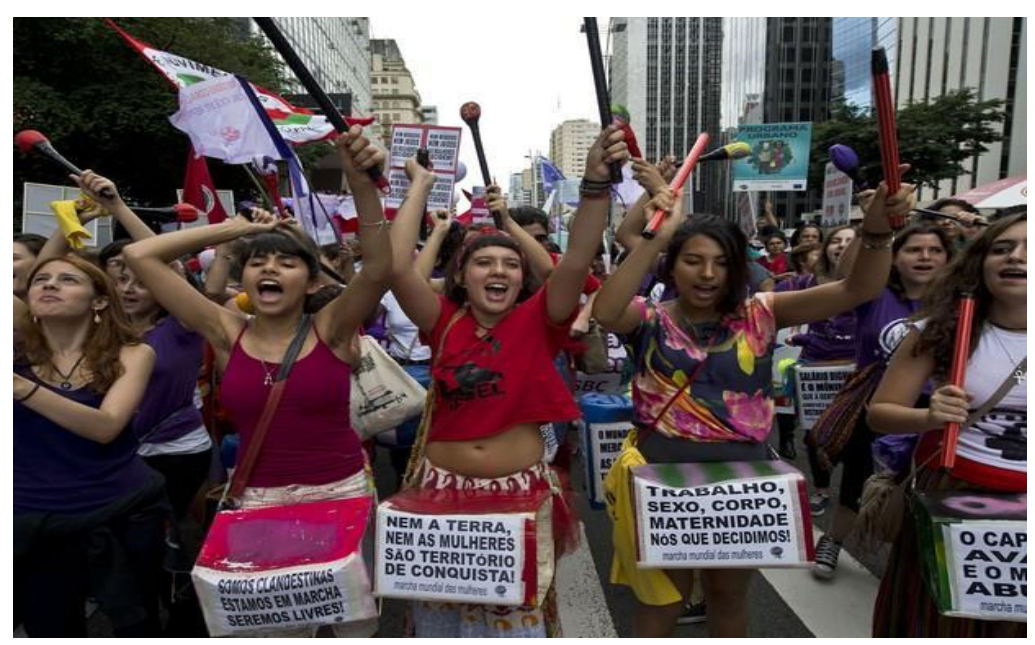

Disponível em: http://g1.globo.com/sao-paulo/noticia/2015/03/mulheres-fazemmanifestacao-e-bloqueiam-avenida-paulista.html Acesso em: 15 de maio de 2019

O sujeito é uma construção historicamente determinada pelas práticas discursivas. Vivemos um momento conturbado politicamente de enfrentamento, e cruzamento de forças, de tensão entre a população e o governo Federal. O sujeito se tece e é tecido por enunciados. Nem sempre ele joga o jogo do poder e quando isso acontece, provocam-se fraturas na ordem social.

\section{Efeitos de Governamentalidade nas ruas: bio ou necropolítica?}

Propomos pensar as manifestações de rua como acontecimentos da história de presente que exibem uma genealogia das práticas de si, a partir de um conjunto de táticas e técnicas de poder que põem em xeque práticas de governamentalidade. Esta não deve ser entendida, como na concepção corrente, pelo exercício de governamento de uma ou mais pessoas à frente da gestão pública ou um conceito relativo à atividade 
exercida por aqueles que conduzem a máquina estatal, mas governar, diz Foucault, "é estruturar o eventual campo de ação dos outros" (2010, p.287) a partir da gestão da vida do corpo populacional.

O conceito de governamentalidade se liga diretamente a três outros que são muito caros a Foucault: sujeito, poder e espaço. Tal conceito é desenvolvido tanto no primeiro volume de "História da Sexualidade I: a vontade de saber", quanto no curso "Em defesa da Sociedade". Entretanto, essa noção foi trabalhada, de modo marcante por esse filósofo, nos cursos ministrados no Collège de France como "Segurança, Território e População" (1978) "Nascimento da Biopolítica" (1979) e no "Do Governo dos Vivos" (1980). Nas palavras de Foucault (1979, p. 291), a governamentalidade é:

o conjunto constituído pelas instituições, procedimento, análises e reflexões, cálculos e táticas que permitem exercer essa forma bastante específica e complexa de poder, que tem por alvo a população, como forma principal de saber a economia política e por instrumentos técnicos essenciais os dispositivos de segurança.

Trata-se de um conjunto de técnicas específicas do exercício de poder que objetiva a gestão da conduta dos indivíduos e da população, incitando, impelindo, proibindo e normatizando seus hábitos, seu lazer, sua saúde, seu trabalho, sua higiene etc. Tais ações são efetuadas por relações sutis de poder e dominação através de estratégias dos aparelhos específicos do governo e embasadas por um conjunto de saberes e por dispositivos de segurança, que agem sobre a realidade de maneira a anular, frear e regular, identificar o que é perigoso, calcular os riscos e intervir sobre as crises.

Foucault já dizia em "História da Sexualidade I: a vontade de saber" que as sociedades modernas não são apenas sociedades de disciplinarização, mas também de normalização dos indivíduos e da população. Ao definir o exercício do poder como "um modo de ação sobre as ações dos outros", ele o caracteriza como governo dos homens, de si para si e de si para os outros. Para este autor, a preocupação com a arte de governar surge a partir do séc. XVI e no século XVIII. A governamentalidade aparece como forma de governo sobre a vida e tem como foco, a população, conjunto de indivíduos que são controlados, têm suas práticas normatizadas, seus corpos adestrados com vistas à máxima produtividade dentro da sociedade capitalista.

O poder sobre a vida desenvolveu-se sobre dois polos: um, individualizante, centrado no corpo do indivíduo, na disciplina com vistas à maximização da produtividade num sistema de aperfeiçoamento contínuo de todas as capacidades 
humanas com vistas à produção de corpos dóceis e úteis. A disciplina é um tipo de organização do espaço. É uma técnica de distribuição dos indivíduos através da inserção dos seus corpos em um espaço fechado, esquadrinhado, hierarquizado (como a escola, a prisão, o asilo). Também se configura como um mecanismo de controle do tempo, pois estabelece uma sujeição do corpo ao tempo, com o objetivo de produzir o máximo de rapidez e o máximo de eficácia. Ela ainda se exerce na vigilância sobre o corpo de modo contínuo e permanente, presente em toda a extensão do espaço.

O segundo polo sobre o qual se exerce o poder sobre a vida se fortaleceu ao longo do século XIX, sem eliminar ou substituir a tecnologia disciplinar, mas agora com a finalidade de conduzir a população e seus processos biológicos. "Tais processos são assumidos mediante toda uma série de intervenções e controles reguladores: uma biopolítica da população" (2014; p. 131). O seu surgimento ocorre simultaneamente ao aparecimento de problemas ligados ao habitat, às condições de vida em uma cidade, à higiene pública.

A biopolítica é uma tecnologia de poder que opera por meio de uma série de intervenções reguladoras no âmbito de uma gestão calculista da vida, na forma de agenciamentos concretos que visam ao investimento sobre o corpo útil, saudável, produtivo, o que caracteriza um poder - biopoder - que tem como desígnio não mais matar - símbolo do poder soberano, mas "fazer viver". O bem-estar dos indivíduos passa a ser a garantia da ordem. Instaura-se uma sociedade em que o poder da lei está integrado ao poder da norma. Isso implica um sistema de vigilância e controle em que há uma visibilidade incessante, uma classificação permanente dos indivíduos, uma hierarquização e o estabelecimento de limites e diagnósticos. A normalização biopolítica das cidades urbanas é feita por meio de práticas de governamentalidade.

Quando Foucault discute sobre as 'artes de governar", ele diz que é preciso primeiro governar bem a si para depois governar o outro. Existem basicamente três tipos de governo: o governo de si ligado à Moral, o governo da família, que diz respeito à Economia e o Governo do Estado, que diz respeito à Política.

Governar um Estado significará portanto, estabelecer a economia ao nível geral do Estado, isto é ter em relação aos habitantes, às riquezas, aos comportamentos individuais e coletivos, uma forma de vigilância, de controle tão atenta quanto a do pai de família". (1979, p.280-281).

Em recorrentes imagens expostas nas mais diferentes mídias, em 2020, o presidente Jair Bolsonaro, em plena pandemia do coronavírus, geralmente não usa máscara e incentiva aglomeração em lugares públicos em meio à maior crise sanitária 
do século XXI. Do ponto de vista da ciência, esta posição significa que ele não consegue cuidar bem de si mesmo e em consequência também não sabe gerir bem a vida da população, que segue muitas vezes seu mau exemplo de negacionista. Pelo lugar que ele ocupa socialmente, o mais alto cargo da nação, suas práticas discursivas e nãodiscursivas têm um poder decisivo no comportamento de grande parcela da população. Como resposta a esta posição, defendida por muitos políticos e empresários, o número de óbitos por COVID-19 no mês de novembro de 2020 ultrapassou os 167 mil e a economia do país segue em crise.

No Brasil do século XXI, precisaríamos de um governante que cuidasse da população, protegendo-a dos efeitos nefastos do coronavírus por meio de uma biopolítica e de dispositivos de segurança que afastassem o medo e o luto da população, ameaçada por um vírus letal. No entanto, o que vemos é exatamente o oposto. Adepto de práticas de governamentalidade neoliberais, nosso presidente conclama o povo às ruas e deixa claro que os índices econômicos do país importam mais do que vidas.

O presidente Jair Messias Bolsonaro se recusou a admitir a gravidade da COVID-19, chamou a doença de "gripezinha" e seus (necro)enunciados, desde o início da pandemia, exibem a falta de respeito, o descaso e a indiferença para com a vida e a saúde do povo brasileiro. Selecionamos apenas alguns enunciados que já viralizaram na internet e entraram para a História. "E daí? Eu sou Messias, mas não faço milagres!" (28 de abril 2020, quando o Brasil computava 5.017 mortes oficiais), assim como: "Lamento as mortes, mas é a realidade. Todo mundo vai morrer aqui. Não vai sobrar nenhum aqui." (22 de maio de 2020, quando o Brasil computava 21.116 mortos). Tais enunciados formam, dentre tantos outros efetivamente ditos pelo presidente em questão, uma rede discursiva que salienta a necropolítica, ou em outras palavras, a prática política da governamentalidade com vistas à naturalização da morte, protagonizada por Bolsonaro neste momento pandêmico.

Em resposta aos pronunciamentos de Bolsonaro, foi exibida no domingo, 09/08/2020, uma faixa de protesto no Viaduto do Chá em São Paulo, composta pelo enunciado que denuncia: "A gripezinha já matou 100 mil brasileiros", seguido pela hashtag \#bolsonarogenocida. Essa politização do vírus pelo governo brasileiro é um fenômeno que singulariza a pandemia e anda de mãos dadas com a "necropolítica" ou "política da morte", termo cunhado pelo filósofo camaronês Achille Mbembe (2018). 


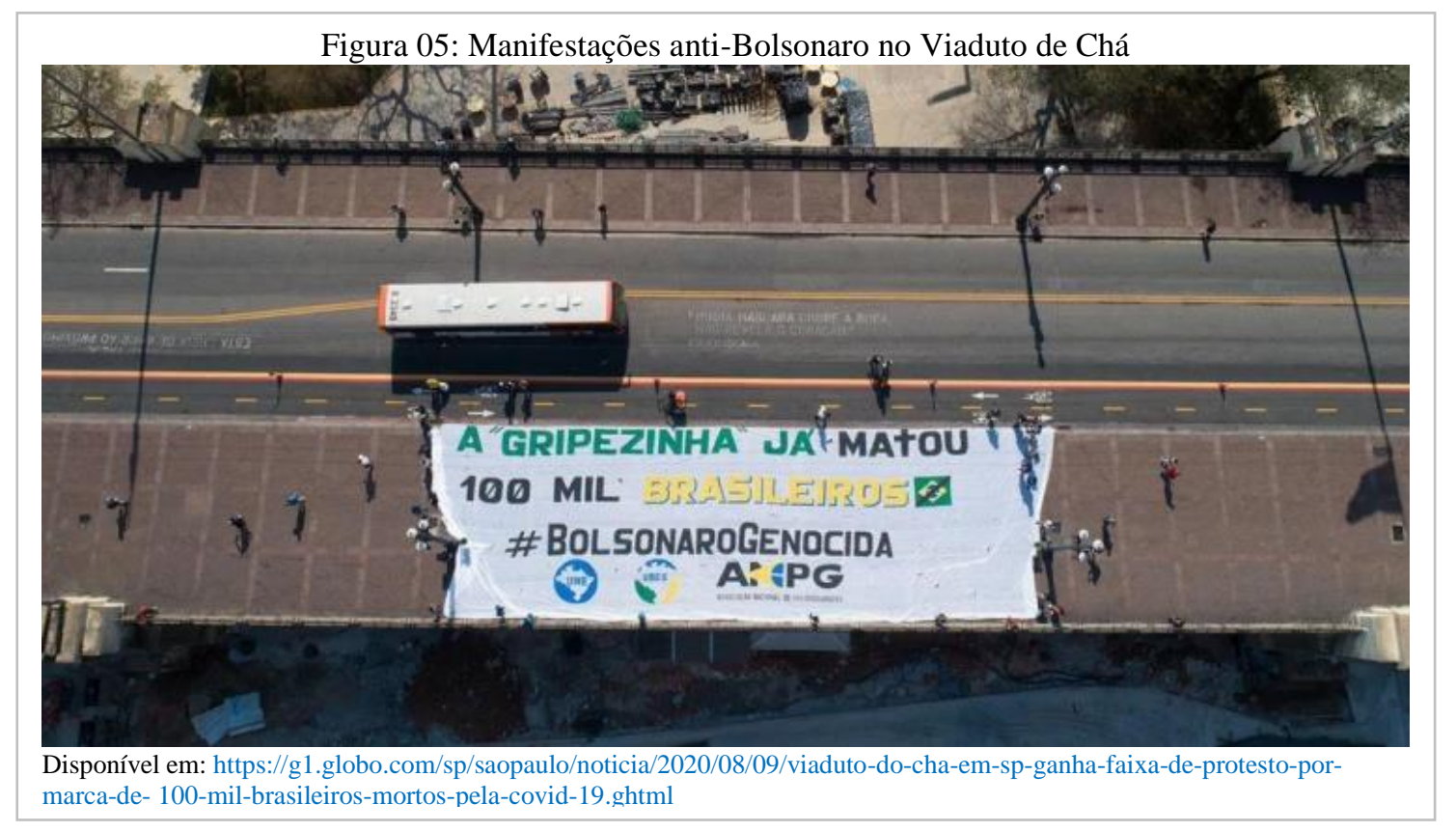

Em consonância com a política negacionista ${ }^{2}$ de Bolsonaro, em 12 de abril de 2020, ocorreu na Avenida Paulista, uma manifestação de rua composta por manifestantes pró-Bolsonaro, ou seja, várias pessoas foram às ruas em São Paulo para apoiar as ações do presidente na conduta da população em relação à crise do COVID19. Para cumprir seus objetivos, os manifestantes usaram um caixão para naquele espaço urbano protestarem publicamente contra o isolamento social em meio a uma crise sanitária que em abril já havia ceifado mais de 70 mil vidas no país. Esse protesto com a passeata do caixão na Avenida Paulista foi inspirado na dança do ritual de morte que acontece em Gana na África. A imagem dos africanos com o caixão viralizou nas redes sociais, que hoje são por excelência lugares de acúmulo, fixação e manutenção de memórias, tanto que a imagem virou meme e GIF (formato de imagens em movimento muito usado nas redes sociais) aqui no Brasil.

Eu chamo a atenção para a apologia da morte, o oposto da biopolítica. Trata-se de um discurso que revira os princípios do bom governo dos homens, de si para si e de si para o outro como diria Foucault. A conduta de grande parte da população brasileira segue o exemplo dado pelo presidente da República. Observamos o exercício de uma necropolítica, a qual parte do pressuposto "de que a expressão máxima da soberania reside em grande medida, no poder e na capacidade de ditar quem pode viver e quem

\footnotetext{
${ }^{2}$ Segundo a Encicloplédia livre Wikipedia, o Negacionismo (do francês négationnisme) é a escolha de negar a realidade como forma de escapar de uma verdade desconfortável. Trata-se da recusa em aceitar uma realidade empiricamente verificável, sendo essencialmente uma ação que não possui validação de um evento ou experiência histórica.
} 
deve morrer, razão pela qual matar ou deixar viver constituem os limites da soberania, seus atributos fundamentais". (2018, p.5) Acrescenta Mbembe: "ser soberano é exercer controle sobre a mortalidade e definir a vida como a implantação e manifestação de poder”. Neste sentido, “a soberania é a capacidade de definir quem importa e quem não importa, quem é 'descartável' e quem não é’”. (2018, p.41). A vocês, caros leitores, deixo a reflexão: Quem são os corpos que importam hoje? Quem tem o poder de decidir quem vive e quem morre nas UTIS com superlotação em decorrência dos casos de coronavírus nos hospitais brasileiros?

\section{Brevíssimas ponderações finais}

Seguindo a esteira do pensamento deleuziano, entendemos que é preciso ter a pretensão de sermos arquivistas e cartógrafos do nosso tempo, para analisarmos os diagramas de força que constituem nossa sociedade. Arquivistas, porque nossas análises se centram nos enunciados que circula(ra)m nas manifestações de rua que aconteceram em solo brasileiro e cartógrafos, porque nosso objetivo é mostrar as relações de saberpoder que permearam as práticas de governamentalidade (por exemplo, a tentativa de implementação de uma necropolítica por parte de Bolsonaro, com seus enunciadosacontecimentos, pois logo viralizam nas redes sociais) e os movimentos de resistência (o grito coletivo nas/das ruas), concomitantes a elas. Entendemos a resistência como inerente ao poder, pensamos com Albuquerque (2015, p. 211) quando ele afirma que "ao resistir não se destrói ou anula o poder, mas se contribui para que seja recriado, deslocado, reinstaurado em novas bases".

E assim a História avança! Os sujeitos urbanos, mesmo limitados por um conjunto de regras e prescrições institucionais, ainda que atuando em um espaço e um tempo limitados, são capazes de driblar a imposição governamental, se subjetivarem, por meio das "linhas de fuga" (DELEUZE, 1990) que escapam dos dispositivos de saber-poder e se reinventarem pela novidade, pela surpresa e pelo inesperado, materializados nos cartazes, nos banners, nas faixas, que visibilizam os anseios populares das ruas e denunciam o estado de insatisfação do povo com as políticas governamentais.

Olhar o discurso com uma visada foucaultiana nos possibilita compreender, analisar, interrogar sobre as nossas práticas cotidianas, a fim de fazermos um diagnóstico do presente, não para reiterar ou refutar "vontades de verdades", mas com o 
objetivo de refletirmos sobre a nossa cota de responsabilidade cidadã nos acontecimentos do nosso tempo e agirmos no afã de uma mudança social.

\section{Referências}

ALBUQUERQUE JR., Durval Muniz.; VEIGA-NETO, Alfredo.; SOUZA FILHO, Alípio de. (orgs.) Cartografias de Foucault. Belo Horizonte: Autêntica, 2008. (Coleção Estudos Foucaultianos)

Edifício em construção ou em ruínas: dos usos e abusos do pensamento de Michel Foucault na contemporaneidade. IN: SOUSA, Kátia Meneses de; PAIXÃO, Humberto Pires. (orgs.) Dispositivos de Poder/Saber em Michel Foucault: biopolítica, corpo e subjetividade. São Paulo: Intermeios; Goiânia: UFG, 2015. pp 209- 221.

CASTRO, Edgardo. Dicionário de Foucault: um percurso pelos seus temas, conceitos e autores. Belo Horizonte: Autêntica, 2009.

DELEUZE, Gilles. O que é um dispositivo? In: DELEUZE, G. Michel Foucault, filósofo. Barcelona: Gedisa, 1990, pp. 155-161.

Foucault. São Paulo: Brasiliense, 2005.

FOUCAUlT, M. A Arqueologia do Saber. Tradução de Luiz Felipe Baeta Neves. 8 ed. Rio de Janeiro: Forense Universitária, 1987.

O sujeito e o poder. In: DREYFUS, Hubert; RABINOW, Paul. Michel Foucault, uma trajetória filosófica: para além do estruturalismo e da hermenêutica. Rio de Janeiro: Forense Universitária, 1995. p. 273-295.

História da sexualidade 1: a vontade de saber. Tradução de Maria Thereza da Costa Albuquerque e J. A. Guilhon Albuquerque. 13 ed. Rio de Janeiro: Edições Graal. 1988.

Microfísica do poder. Org. e Trad. de Roberto Machado. 14 ed. Rio de Janeiro. Edições Graal. 1979.

Vigiar e punir: nascimento da prisão. 41 ed. Petrópolis, RJ: Vozes, 2014.

Estratégia, poder-saber. Ditos e escritos IV. Rio de Janeiro: Forense Universitária, 2003.

- Ditos \& Escritos V: Ética, Sexualidade, Política. 2ed.Rio de Janeiro: Forense Universitária, 2006.

VEYNE, Paul. Foucault: seu pensamento, sua pessoa. Rio de Janeiro: Civilização Brasileira, 2011. 